\title{
Números complexos: um objeto de aprendizagem para ensinar e aprender
}

Cassiano Scott Puhl c.s.puhl@hotmail.com 0000-0003-0696-5666

Pontifícia Universidade Católica do Rio Grande do Sul

Isolda Gianni de Lima iglima1@gmail.com

0000-0002-6335-3079

Universidade de Caxias do Sul
RESUMO

Este artigo apresenta um recorte de uma pesquisa de mestrado que criou e analisou um objeto de aprendizagem (OA) como recurso digital para o ensino de números complexos no Ensino Médio. O OA tem o objetivo de promover aprendizagem ativa e significativa, por meio de interações com aplicativos disponíveis virtualmente, desenvolvidos no Geogebra. Neste artigo, descreve-se o OA e apresenta-se o resultado da avaliação desse recurso. A avaliação seguiu um modelo proposto pelo Centro Interdisciplinar de Novas Tecnologias na Educação da Universidade Federal do Rio Grande do Sul (UFRGS), no qual são considerados aspectos pedagógicos e técnicos, utilizando uma escala para a avaliação de cada critério. Por fim, o OA mostrou bons indicativos, assim tem-se a expectativa de que o OA possa ser utilizado por outros professores.

PALAVRAS-CHAVE: Números complexos. Objeto de aprendizagem. Ensino Médio. Recurso didático. 


\section{INTRODUÇÃO}

A evolução da tecnologia, principalmente da internet, fez com que a escola repensasse seu papel na sociedade, pois durante décadas teve o objetivo de formar pessoas, especialistas, com um conhecimento vasto sobre uma única área de conhecimento. Entretanto, no final de década de 2010, a realidade e a demanda são outras, frente às novas configurações culturais, sociais e pessoais que estão se desenvolvendo.

A sociedade contemporânea clama por cidadãos críticos e criativos, que saibam lidar com problemas sociais e que também conheçam seus direitos e deveres que têm para consigo mesmos e para a sociedade (MORETTO, 2007).

Nesse sentido, o ensino precisa se constituir como um processo educativo significativo, contribuindo para formar estudantes críticos e criativos. Para que isso ocorra, é preciso repensar as práticas pedagógicas e as estratégias de ensino, e buscar novos recursos que atualizem e inovem os processos de aprendizagem. As tecnologias de informação e comunicação (TIC) podem auxiliar o professor a promover um ambiente propício para que o estudante seja ativo na aprendizagem de novos conceitos. Porém, não adianta simplesmente utilizar a tecnologia sem a orientação de uma corrente filosófica, ou apenas para expor conteúdos (MASSETO, 2013).

As tendências educacionais atuais precisam ser levadas em consideração no processo de criação e na aplicação das TIC em sala de aula, pois elas não objetivam simplesmente substituir velhos recursos; acima de tudo, a tecnologia deve ser capaz de instaurar um ambiente reflexivo e investigativo, tornando as aulas mais interessantes e desafiadoras (MASSETO, 2013).

Em relação ao ensino de matemática, a utilização de novas estratégias se mostram necessárias para uma aprendizagem significativa. A partir dos anos 2000, alguns conteúdos de matemática básica não têm sido mais ministrados nas escolas, devido à restrição da carga horária ou por serem considerados menos importantes. O estudo dos números complexos é um exemplo, como mostram as pesquisas de Batista (2004) e de Mello e Santos (2005).

Diante desse cenário, procurando evidenciar a utilidade e importância do conteúdo, criou-se um objeto de aprendizagem (OA), denominado "Números Complexos: interação e aprendizagem", para o ensino de números complexos no Ensino Médio, que está disponível em http://matematicacomplexa.hol.es/. Os objetos de aprendizagem são recursos digitais dinâmicos, interativos e reutilizáveis, que podem ser aplicados em diversas modalidades de ensino (AUDINO, 2012).

Em busca de outros estudos que abordassem a criação de objetos de aprendizagem para o ensino de números complexos no Ensino Médio, foram constatadas duas pesquisas, uma desenvolvida por Monzon (2012) e outra por Pinto $(2015)^{2}$, que relatam a utilização do Geogebra para representar o sentido geométrico dos números complexos.

Na pesquisa de Monzon (2012) participaram 26 estudantes do terceiro ano do Ensino Médio, em que se criou um objeto de aprendizagem denominado "Números Complexos", com animações interativas, aplicativos do Geogebra, vídeos, explicações e exercícios. O objetivo da pesquisa foi aprimorar o ensino dos 
números complexos e introduzir os conceitos das funções de variável complexa sob um ponto de vista geométrico. As animações permitiram que os estudantes constatassem o efeito provocado sobre números complexos no plano em decorrência de operações, por meio da geometria dinâmica, o qual seria mais difícil de ser percebido sem o apoio de recursos computacionais. Desse modo, Monzon (2012) afirma que é possível promover um ensino mais significativo com o auxílio de tecnologias, e ainda introduzir o conceito de funções de variável complexa.

A pesquisa de Pinto (2015), por sua vez, teve como amostra 20 estudantes do segundo ano do Curso Técnico em Equipamentos Biomédicos, da área de eletroeletrônica do Centro Federal de Educação Tecnológica de Minas Gerais. O autor criou um objeto de aprendizagem denominado "Descomplicando os Complexos", com aplicativos dos softwares Geogebra e Exelearning. No ambiente desse objeto de aprendizagem foram propostas oito atividades, sendo duas voltadas para o Ensino Médio e seis para o Ensino Médio Técnico, cujo propósito do autor foi sugeri-las, como um contexto interdisciplinar, para professores de Matemática, como aplicações desses números na área de eletroeletrônica.

Os resultados da pesquisa de Pinto (2015) foram satisfatórios com os estudantes de Ensino Médio Técnico, que já haviam estudado números complexos antes de utilizar o OA, e que ampliaram esse conhecimento aplicando-o em circuitos elétricos. Pinto afirma que o objeto de aprendizagem cumpriu o seu papel, uma vez que, por meio da comunicação com o sistema, proporcionou a interação entre os estudantes e as atividades propostas, além de estimulá-los a fazerem experimentações e simulações.

A dissertação da qual procede este artigo $^{3}$ mostrou, igualmente, indícios de que o OA é um recurso com potencial didático diferenciado, pois permite que o estudante manipule, experimente, teste hipóteses e conclua, por si mesmo, sobre ideias e resultados de operações com números complexos, construindo de forma ativa seu conhecimento. Além dessas constatações, procurou-se ainda, avaliar o OA como um recurso de aprendizagem, utilizando um modelo adaptado da Tarouco (2004); o que difere o estudo realizado das pesquisas de Monzon (2012) e de Pinto (2015), pois não se encontrou, nessas, registros de tal avaliação.

Este artigo, sendo um recorte de uma pesquisa de mestrado que criou e analisou um OA como um recurso de aprendizagem e que mostrou indícios do desenvolvimento de uma aprendizagem significativa dos conceitos e operações com números complexos, objetiva descrever brevemente o OA e apresentar resultados da avaliação da sua aplicação com estudantes do Ensino Médio.

\section{FUNDAMENTAÇÃO TEÓRICA}

As tecnologias podem auxiliar a criação de ambientes de aprendizagem que sugerem novas formas de pensar e aprender (BARIN; BASTOS; MARSHALL, 2013). A escola, como instituição social, não pode abrir mão dessas ferramentas de apoio (BRASIL, 2002); mas deve promover a sua utilização de forma correta, consoante aos objetivos traçados pelo docente para o trabalho com determinado conteúdo.

Nesse contexto, é muito importante o conceito de transposição didática, proposto por Chevallard (1991 apud ALMOULOUD, 2007, p. 5) definindo-o como "o conjunto de transformações por que passa um saber sábio, a fim de ser ensinado". A transposição didática é o trabalho realizado para transformar o saber 
científico em algo a ser ensinado. A transposição didática procura deixar o conteúdo compreensível, com sentido para o significado desse conteúdo e para a sua veracidade.

O professor deve procurar ser criativo para inovar nas suas estratégias de aprendizagem, transformando os conteúdos em ensináveis, sem perder a veracidade do conhecimento e sem esquecer de todo o contexto em que o estudante está inserido. Desse modo, a transposição didática reflete nos processos de ensino e de aprendizagem, pois integra "[...] reflexões sobre a aprendizagem, além de determinar novos conteúdos e novas formas de ensinar esses conteúdos deve considerar a questão da preparação dos professores para essas novas formas de ensino" (BELLEMAIN, 2000, p. 200). Nessa perspectiva, o professor deve tomar alguns cuidados para que consiga, efetivamente, fazer uma transposição didática.

Na década de 1990, a transposição didática foi ampliada por Balacheff (apud BELLEMAIN, 2000), que criou uma extensão, sendo essa a transposição informática (BELLEMAIN, 2000), e que é um dos processos fundamentais para uma boa arquitetura de um objeto de aprendizagem. A diferença da transposição informática para a didática consiste no fato de que a transformação dos saberes é mediada por meio da utilização de computadores. Para isso ocorrer, é preciso considerar uma série de fatores, como: didatização, interface gráfica, recursos de hardware e o conteúdo a ser ensinado.

Além disso, a criação dos aplicativos envolve programação, parte gráfica e planejamento pedagógico (FERNANDEZ; RIGO, 2012). Essas três competências referidas podem ou não estar presentes no desenvolvedor, ou seja, no programador que busca criar um OA com potencial para o desenvolvimento de uma aprendizagem autônoma, propiciando o emprego de estratégias construtivistas e interacionistas.

A geometria dinâmica e interativa pode ser utilizada pelos professores no processo de construção do conhecimento. Existem vários softwares e também objetos de aprendizagem que podem auxiliar, principalmente, na visualização geométrica, possibilitando a exploração de diferentes situações e a construção de conjecturas que colaboram para dar sentido a ideias e conceitos. Ao construir uma figura geométrica com esses softwares, o estudante passa a ter um ponto de partida, podendo, então, realizar testes transformando-a quantas vezes quiser, em novas experimentações, visando reformar, confirmar ou refutar suas conjecturas (GRAVINA, 1996).

Em relação aos objetos de aprendizagem, é importante afirmar que não existe uma definição mundialmente aceita do conceito. Dentre vários conceitos de OA, um que aparece com frequência em comunicações científicas é "qualquer recurso digital que possa ser reutilizado para dar suporte à aprendizagem" (WILEY, 2000, p. 3). Não se trata de nova proposta pedagógica, mas de recurso de apoio à aprendizagem ou, por vezes, de estratégia de aprendizagem para construir conhecimento significativo e os saberes dos jovens. As características presentes no OA são: reutilização, flexibilidade, acessibilidade, fragmentação, dinamização, armazenamento de dados e a interoperabilidade.

Visando analisar esses fatores, seguiu-se um processo de avaliação, baseado em um modelo proposto por Tarouco (2004). Os estudantes que utilizaram o OA receberam formulários para avaliar aspectos pedagógicos e técnicos referentes à qualidade de conteúdo, usabilidade e potencial como ferramenta de ensino. No 
seu modelo de avaliação, Tarouco utiliza um sistema reconhecido na comunidade científica, intitulado Multimedia Educational Resource for Learning and Online Teaching (Merlot) $)^{4}$ e, para facilitar a avaliação, o teórico sugere a utilização da escala ${ }^{5}$ EDUCAUSE 2001, que serve para agilizar a avaliação e obter dados mais precisos.

Neste estudo, para a qualidade de conteúdo do OA foram avaliados os seguintes itens: $O A$ apresenta informações precisas; $O A$ inclui quantidade adequada de material; OA demonstra um conceito-base; OA resume bem os conceitos.

Sobre a usabilidade do OA foram avaliadas as seguintes características: é fácil andar pelos diferentes espaços que o compõe; tem instruções claras de uso; o ambiente é motivador; é visualmente atraente; é interativo; a linguagem utilizada é adequada e sem erros ortográficos; a linguagem matemática é adequada e sem erros.

Em relação ao OA como ferramenta de ensino, foram avaliados os seguintes critérios: identifica objetivos de aprendizagem; reforça conceitos progressivamente; demonstra relações entre conceitos; fundamenta conceitos prévios; é eficiente (pode-se aprender muito em curto período de tempo).

\section{DESCRIÇÃO DO OA}

O OA, denominado "Números Complexos: interação e aprendizagem", foi criado e analisado na pesquisa de mestrado, e está disponível em: $<$ matematicacomplexa.hol.es>. Para a sua construção, buscou-se propor um recurso para que a aprendizagem de números complexos seja dinâmica, agradável e dialógica. O OA, cuja página de entrada aparece na Figura 1, pode ser utilizado como material de apoio em sala de aula ou em atividades complementares aos estudos em classe e serve, também, para estudantes que querem realizar uma aprendizagem autônoma do conteúdo, sem a orientação de um professor ou a obrigatoriedade de percorrer uma sequência definida de passos, atividades ou leituras a realizar. 
Figura 1 - Homepage do OA

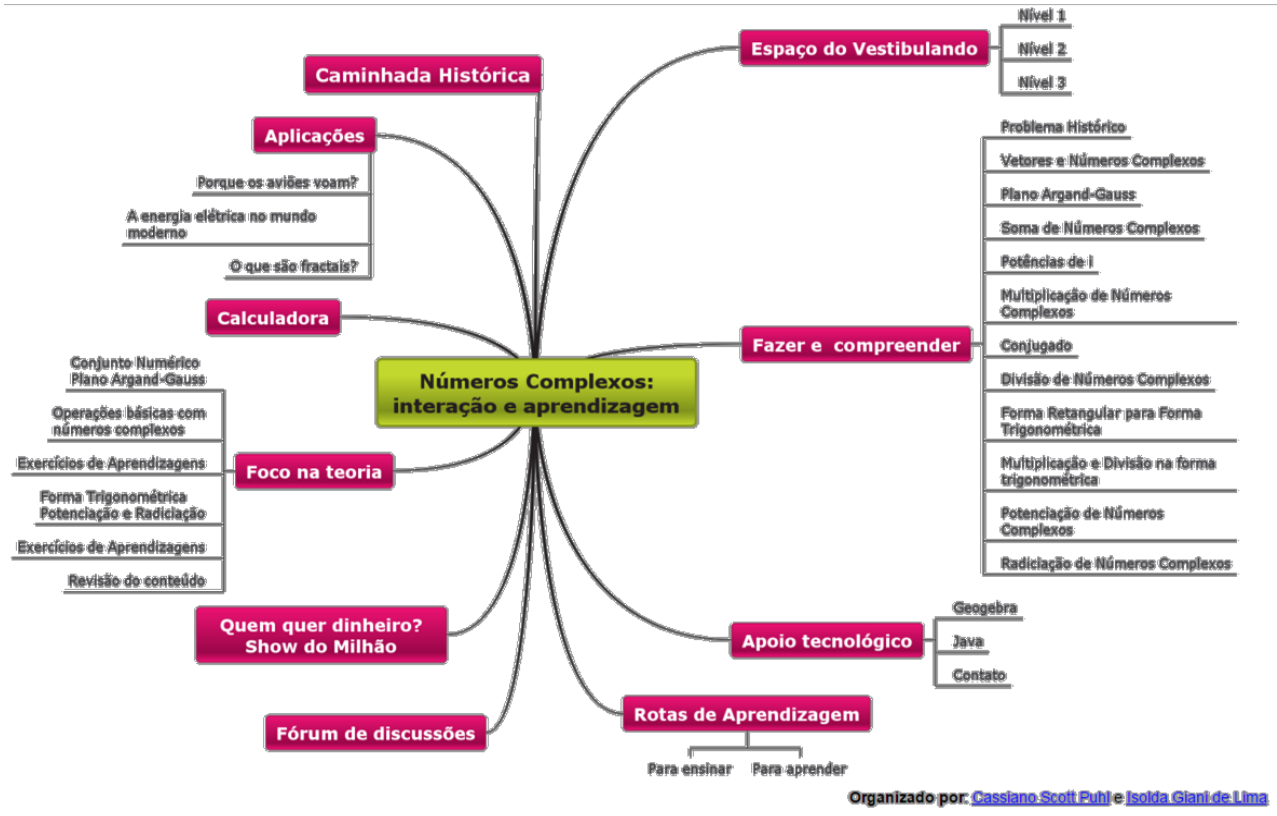

(Fonte: Elaborada pelos autores)

O objeto de aprendizagem é constituído de dez espaços: "Caminhada histórica", "Espaço do vestibulando", "Fazer e compreender", "Apoio tecnológico", "Rotas de Aprendizagem", "Quem quer dinheiro?", "Show do Milhão", "Foco na teoria", "Calculadora", "Aplicações e Fórum de discussões". A seguir, descreve-se, brevemente, cada um dos espaços.

O espaço "Caminhada histórica" (Figura 2) é estruturada como uma linha do tempo, em que são apresentados os matemáticos que contribuíram para a formulação da teoria dos números complexos.

Figura 2 - Imagem da linha do tempo da "Caminhada histórica"

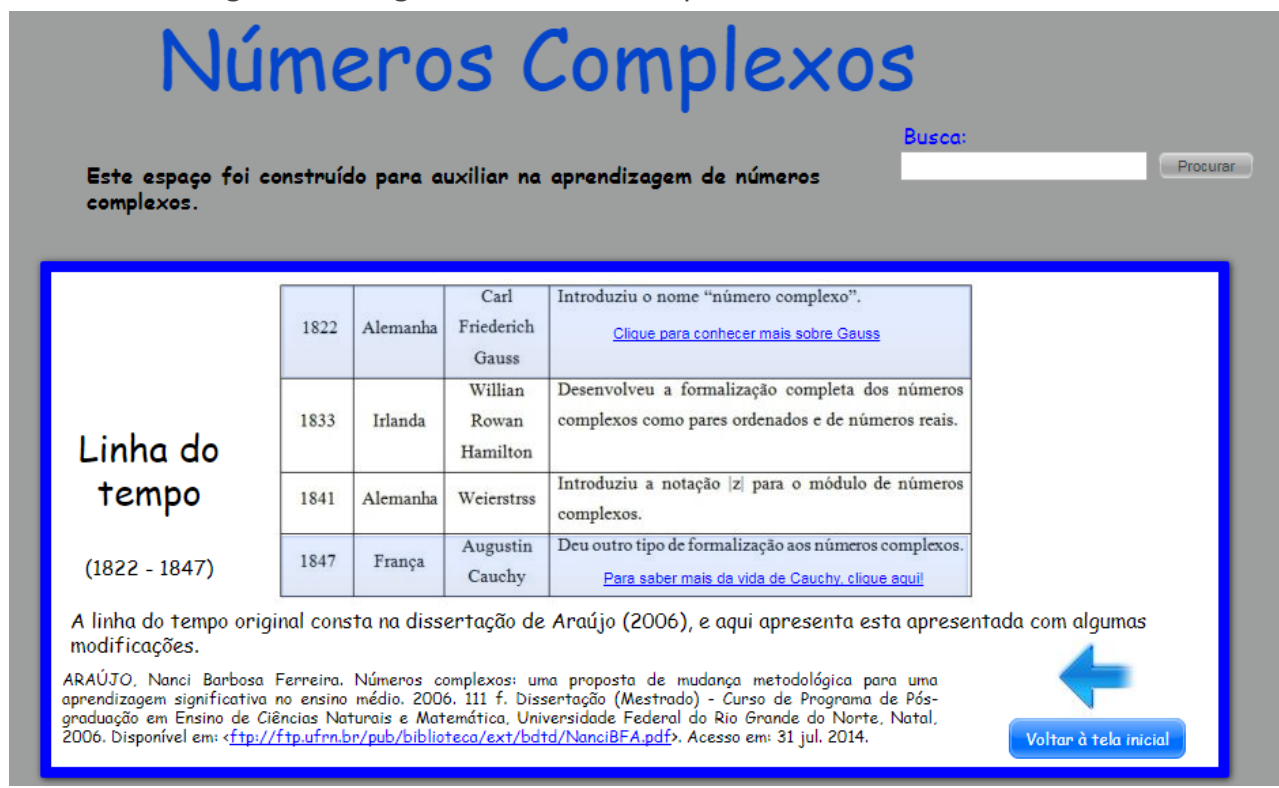

(Fonte: Elaborada pelos autores) 
O "Espaço do vestibulando" constitui uma coletânea de questões sobre números complexos, que foi preparada como resultado de uma pesquisa realizada em provas de vestibular de universidades federais do Brasil e de outras que se destacam na oferta de cursos da área das Ciências Exatas e Tecnologia do estado do Rio Grande do Sul.

Para o espaço de aprendizagem "Fazer e compreender" (Figura 3) foi construída uma sequência de aplicativos no Geogebra, com atividades potencialmente significativas para a aprendizagem de números complexos.

Um "Apoio tecnológico" foi criado como apoio a questões relacionadas ao software Geogebra, que requer o programa Java para programar e rodar os aplicativos. O Java, por sua vez, precisa de uma atualização que, para quem não tem familiaridade com a informática, não é um procedimento comum. Assim, nesse espaço são propostas soluções para alguns problemas recorrentes.

Figura 3 - Uma tela do espaço "Fazer e compreender"

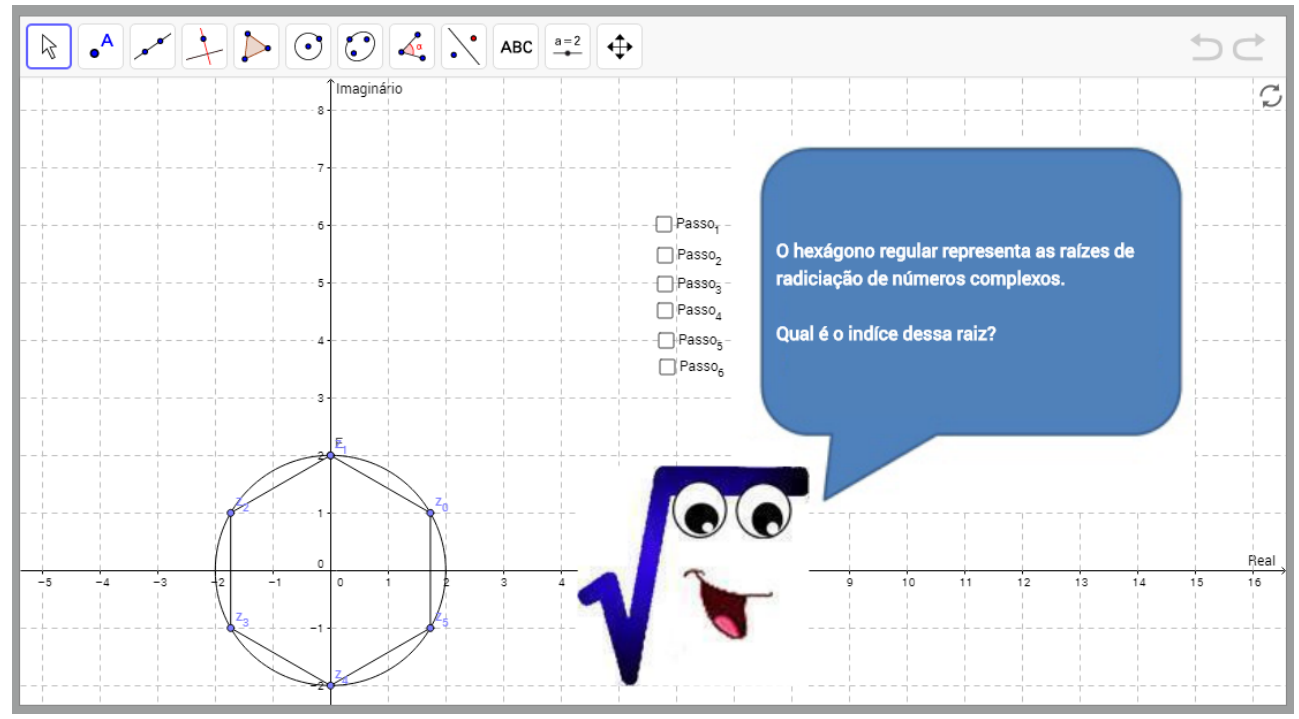

(Fonte: Elaborada pelos autores)

"Quem quer dinheiro?" (Figura 4) é uma expressão bastante conhecida e sugere o lúdico. Para desafiar e estimular os estudantes, nesse espaço criou-se um "Show do Milhão", alusivo a um programa da televisão brasileira, com perguntas sobre números complexos. 


\section{Números Complexos}

Este espaço foi construído para auxiliar na aprendizagem de números complexos.

\section{O Show do Milhão possui perguntas envolvendo operações} básicas até a forma trigonométrica do número complexo.

Encontramos dificuldade na escrita de expressões, desta forma, vamos colocar alguns exemplos de expressões que podem aparecer no programa.

sqrt 8 - significa a raiz quadrada do número 8. zw ou z.w - expressa a multiplicação de $z$ por $w$.

$z / w$ - indica a divisão de $z$ por $w$.

$$
\operatorname{sqr}+8[\cos (5 \mathrm{pi} / 4)+\mathrm{isen}(5 \mathrm{pi} / 4)]=\sqrt{8} \cdot\left(\cos \frac{5 \pi}{4}+i \cdot \operatorname{sen} \frac{5 \pi}{4}\right)
$$

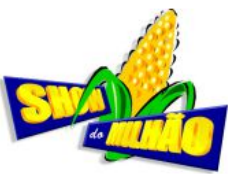

0 arquivo baixado estará zipado. Faça o download, abra-o e depois execute arquivo Schow.exe para jogar.

Clique para baixar o jogol

(Fonte: Elaborada pelos autores)

Em "Foco na teoria", são apresentados conceitos formais da teoria dos números complexos.

Em "Calculadora", são propostas formas de como operar com números complexos nas calculadoras científicas, Casio e HP, bastante utilizadas por estudantes do Ensino Médio ou de cursos de Engenharia. Assim, agregaram-se vídeos explicativos, disponibilizados no YouTube, de como se opera com números complexos nessas calculadoras.

No espaço "Aplicações", são apresentadas situações reais, nas quais números complexos podem ser identificados, descritas em linguagem compreensível para estudantes de Ensino Médio. Tais situações foram pesquisadas e construídas com a colaboração de professores universitários e de cursos técnicos, que sugeriram bibliografias com aplicações que auxiliam a dar substantividade ao conteúdo.

O "Fórum de discussões" permite aos estudantes expor dúvidas e serem auxiliados por professores e/ou outros estudantes. A troca de experiências e a oportunidade que todos têm de apresentar e discutir possíveis soluções aos problemas apresentados propicia uma construção reflexiva sobre números complexos.

Por fim, em "Rotas de aprendizagem" são sugeridos percursos pelo OA que podem ser seguidos tanto por professores, adaptando-os a seus planejamentos, quanto por estudantes que desenvolvem uma aprendizagem autônoma. Este ambiente contempla uma proposta de sequência de aulas com atividades potencialmente significativas para a aprendizagem dos números complexos por meio de estratégias ativas.

Cada espaço foi criado com o propósito de atender a diversidade de estudantes que estão presentes nas salas de aulas ou em outros espaços de aprendizagem. Assim, cada um pode escolher por quais espaços quer passar e em qual ordem, conforme a sua necessidade, o seu interesse e a sua forma de estudar e aprender, podendo dedicar-se a leituras, resolução de exercícios, vídeos e vídeo 
aulas, realizar atividades lúdicas e interagir com um personagem virtual que propõe reflexões e orientações para construir conhecimento.

\section{ASPECTOS METODOLÓGICOS}

Os participantes da pesquisa, que interagiram e avaliaram o OA, foram 18 estudantes do terceiro ano do Ensino Médio de uma escola pública do Rio Grande do Sul. Desses, 15 eram também trabalhadores, que exerciam alguma função em mercados, escolas de Educação Infantil, escritórios de contabilidade, atelier de costura ou na lavoura, como ajudantes de seus pais.

O instrumento de coleta de dados foram questionários que continham questões mistas, para que o estudante expresse sua opinião sobre os ambientes e os aplicativos do Geogebra. Para a elaboração das questões, utilizou-se também um modelo de avaliação de OA proposto por Tarouco (2004). Os questionários foram disponibilizados aos estudantes em etapas, após terem realizado estudos sobre propriedades ou operações de números complexos com o auxílio do OA.

Em relação a avaliação dos ambientes de aprendizagem do $\mathrm{OA}$, conforme proposto por Tarouco (2004), foram considerados aspectos pedagógicos e técnicos, utilizando-se a escala Likert para a avaliação de cada critério. A escala proposta vai de 5 a 1 , sendo esses graus que correspondem a: 5 - Concordo plenamente; 4 - Concordo; 3 - Não concordo nem discordo; 2 - Discordo; 1 Discordo totalmente. Além desses, há a opção SR - Sem resposta, para os casos em que, segundo o respondente, nenhum grau de avaliação é aplicável.

A análise realizada é predominante quantitativa, no qual os dados coletados foram tabulados e analisados por meio da estatística descritiva. Além disso, selecionou-se relatos dos estudantes para aumentar os indícios para a qualificação do $O A$, confirmando os dados analisados estatisticamente. Sendo assim, inicialmente, apresenta-se a análise sobre a avaliação do $\mathrm{OA}$ e, posteriormente, os relatos de estudantes como forma de respaldar os resultados evidenciados.

\section{DISCUSSÃO E ANÁLISE DO OA}

A presente pesquisa busca avaliar se um estudante que interage sozinho no $\mathrm{OA}$, sem a presença de um professor, tem condições de construir conhecimentos sobre números complexos. Os dados coletados e avaliação do OA servem também para qualificar o OA, quando utilizado com a orientação do professor, da forma como ocorreu na parte experimental desta pesquisa.

Os ambientes utilizados e avaliados durante a pesquisa foram: "Fazer e compreender", "Caminhada histórica", "Aplicações" e "Show do Milhão". Como não é possível abordar a avaliação detalhada de cada ambiente, organizou-se a Tabela 1 que é uma avaliação geral do OA, com média dos resultados das avaliações dos ambientes, realizadas pelos estudantes.

Tabela 1 - Avaliação geral do OA

\begin{tabular}{c|c|c|c|c|c|c}
\hline Critérios & $\mathbf{5}$ & $\mathbf{4}$ & $\mathbf{3}$ & $\mathbf{2}$ & $\mathbf{1}$ & SR $^{*}$ \\
\hline $\begin{array}{c}\text { O OA apresenta informações } \\
\text { precisas }\end{array}$ & $45 \%$ & $44 \%$ & $5 \%$ & & & $6 \%$ \\
\hline
\end{tabular}




\begin{tabular}{|c|c|c|c|c|c|c|}
\hline $\begin{array}{l}\text { O OA inclui quantidade adequada de } \\
\text { material }\end{array}$ & $54 \%$ & $34 \%$ & $8 \%$ & & & $4 \%$ \\
\hline O OA demonstra um conceito-base & $53 \%$ & $35 \%$ & $7 \%$ & & & $5 \%$ \\
\hline O OA resume bem os conceitos & $51 \%$ & $39 \%$ & $6 \%$ & & & $4 \%$ \\
\hline É fácil andar pelo ambiente & $54 \%$ & $35 \%$ & $5 \%$ & $2 \%$ & & $4 \%$ \\
\hline $\begin{array}{l}\text { O ambiente tem instruções claras de } \\
\text { uso }\end{array}$ & $56 \%$ & $32 \%$ & $7 \%$ & $1 \%$ & & $4 \%$ \\
\hline O ambiente é motivador & $42 \%$ & $39 \%$ & $10 \%$ & $2 \%$ & $3 \%$ & $4 \%$ \\
\hline O ambiente é visualmente atraente & $26 \%$ & $49 \%$ & $16 \%$ & $4 \%$ & & $5 \%$ \\
\hline O ambiente é interativo & $52 \%$ & $31 \%$ & $13 \%$ & & & $4 \%$ \\
\hline $\begin{array}{l}\text { A linguagem é adequada e sem } \\
\text { erros ortográficos }\end{array}$ & $51 \%$ & $35 \%$ & $5 \%$ & $3 \%$ & $1 \%$ & $5 \%$ \\
\hline $\begin{array}{l}\text { A linguagem matemática é } \\
\text { adequada e sem erros }\end{array}$ & $55 \%$ & $33 \%$ & $5 \%$ & $3 \%$ & & $4 \%$ \\
\hline $\begin{array}{c}\text { Como recurso de aprendizagem, } \\
\text { identifica objetivos de } \\
\text { aprendizagem }\end{array}$ & $51 \%$ & $42 \%$ & $3 \%$ & & & $4 \%$ \\
\hline $\begin{array}{l}\text { Como recurso de aprendizagem, } \\
\text { reforça conceitos progressivamente }\end{array}$ & $40 \%$ & $45 \%$ & $6 \%$ & $1 \%$ & & $8 \%$ \\
\hline $\begin{array}{l}\text { Como recurso de aprendizagem, } \\
\text { demonstra relações entre conceitos }\end{array}$ & $38 \%$ & $49 \%$ & $7 \%$ & & & $6 \%$ \\
\hline $\begin{array}{l}\text { Como recurso de aprendizagem, } \\
\text { fundamenta em conceitos prévios }\end{array}$ & $36 \%$ & $41 \%$ & $16 \%$ & $1 \%$ & & $6 \%$ \\
\hline $\begin{array}{l}\text { Como recurso de aprendizagem, é } \\
\text { eficiente (pode-se aprender muito } \\
\text { em curto período de tempo) }\end{array}$ & $52 \%$ & $39 \%$ & $3 \%$ & $2 \%$ & & $4 \%$ \\
\hline
\end{tabular}

Os dados da Tabela 1 sugerem que o OA foi um recurso potencialmente significativo, pois em todos os aspectos, a maioria dos estudantes avaliou com "concordo" ou "concordo plenamente".

Fernandez e Rigo (2012) afirmam que, para a criação de objetos educacionais, é necessário levar em consideração três fatores: a programação, a parte gráfica e o planejamento pedagógico. A programação do OA não é possível de ser avaliada com este instrumento. Contudo, dentre os cinco aspectos mais bem avaliados, observa-se sua relação com os outros dois fatores. Os aspectos "o ambiente tem instruções claras de uso", "a linguagem matemática é adequada e sem erros" e "é 
fácil andar pelo ambiente" podem ser consideradas como designer do OA, ou seja, sua parte gráfica. Além dessas características, houve destaque também para os aspectos "o OA inclui quantidade adequada de material" e "o OA demonstra um conceito-base", qualidades relacionadas com a aprendizagem, ou seja, com o planejamento pedagógico.

Ao se construir o $\mathrm{OA}$, deu-se atenção especial para a criação de um ambiente de fácil interação que se constituísse num espaço de aprendizagem em que os estudantes pudessem aprender conceitos fundamentais de forma dinâmica e rápida. $\mathrm{E}$, tendo sido esses aspectos os mais bem avaliados, tem-se o sentimento de ter atingido os objetivos propostos para o OA. Todo esforço, estudo e tempo de dedicação para esta criação rendeu bons frutos, como pretendido.

No entanto, outros aspectos não foram tão bem avaliados, como: "O ambiente é visualmente atraente", "Como recurso de aprendizagem, fundamenta em conceitos prévios" e "Como recurso de aprendizagem, demonstra relações entre conceitos". O primeiro refere-se à parte gráfica e, infelizmente, ao construir um OA sem buscar o apoio de um profissional especializado, ficou difícil conseguir bons índices neste aspecto.

Em relação aos outros dois aspectos: "Como recurso de aprendizagem, fundamenta em conceitos prévios" e "Como recurso de aprendizagem, demonstra relações entre conceitos"; os dados da pesquisa não contradizem os objetivos almejados na criação do OA. Mesmo levando em consideração os dados apresentados, cabe uma reflexão: Será que o estudante percebeu que existia uma relação entre os conceitos desenvolvidos? É preciso compreender a unidade imaginária para aprender sobre os números complexos; e parece que o estudante não percebeu essa dependência. Então, cabe considerar a hipótese de que o estudante não identificou a relação entre os conceitos desenvolvidos, pois o novo conhecimento relaciona-se diretamente com um conhecimento prévio.

Dessa forma, ao utilizar e interagir com o OA, o estudante compreendia o conhecimento, permitindo o desenvolvimento de novas aprendizagens. Assim, mesmo sendo alguns dos três aspectos não tão bem avaliados, têm-se indícios de que $\mathrm{O} \mathrm{OA}$, como recurso de aprendizagem, constitui-se num material potencialmente significativo.

Além da avaliação do OA têm-se relatos de estudantes como indícios de se ter construído um bom recurso para aprendizagem de números complexos. Por exemplo, na Figura 5 tem-se pareceres de estudantes, em relação ao ambiente "Fazer e compreender", especificamente sobre o espaço "Vetores e Números Complexos", considerado como fonte de conhecimento, em que os aplicativos do Geogebra explicavam e interagiam com os estudantes, permitindo a construção do conhecimento de forma autônoma. 
Figura 5 - Relatos de estudantes sobre os aplicativos do Geogebra.

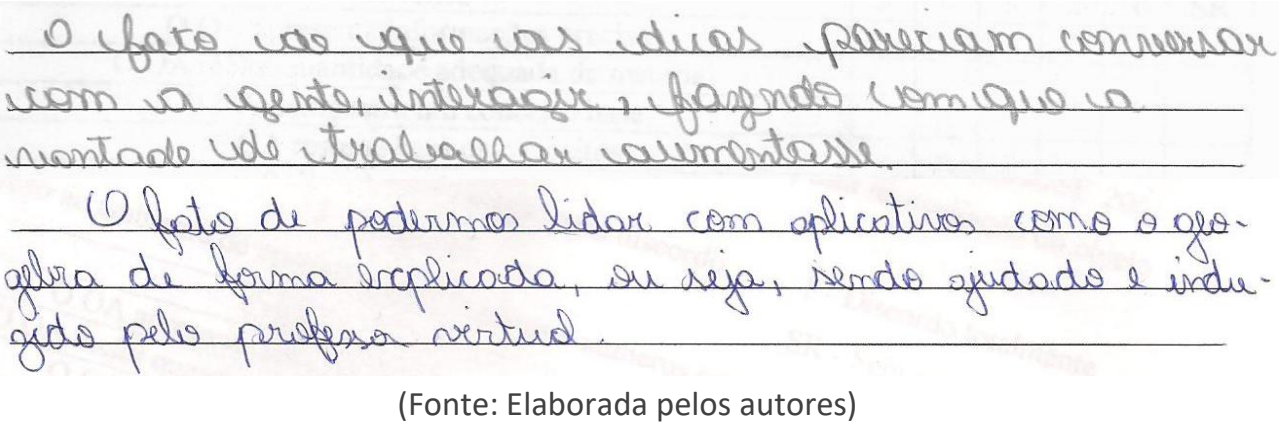

Em um dos questionários, uma das questões destinava-se à avaliação do nível de interação e de compreensão dos conceitos abordados nos aplicativos do Geogebra. As respostas, $72 \%$ dos estudantes responderam satisfatoriamente e $28 \%$ afirmaram plenamente. Esses índices indicam que os aplicativos desempenharam, na perspectiva dos estudantes, um papel fundamental para a compreensão, especialmente, do conceito de unidade imaginária, propiciando um ambiente reflexivo que contribuiu para a construção de novos conhecimentos.

Desse modo, os aplicativos propiciaram a ampliação dos conhecimentos de conjuntos numéricos e da raiz quadrada de número negativo. Ao relatarem que interagiram satisfatoriamente ou plenamente, os estudantes confirmaram que estiveram dispostos a resolver os desafios e aprender o conteúdo proposto nos aplicativos, num ambiente dinâmico e reflexivo, revelando sua predisposição para a aprendizagem.

\section{CONSIDERAÇÕES FINAIS}

Planejar um recurso digital, especificamente um OA, com o propósito de criar um ambiente propício para a interação, a troca de ideias, para gerar testes de hipóteses e construção de conhecimentos, foi o desafio que se teve, sendo parte dos resultados dessa construção apresentada neste trabalho. O OA aqui proposto configura-se como um ambiente planejado para ser um recurso potencialmente significativo, no qual os estudantes podem manipular os objetos geométricos e, assim, aumentar significativamente a chance de compreender, pelo menos a nível introdutório, o significado dos conceitos.

O objetivo deste artigo foi avaliar o OA como um recurso de aprendizagem. A análise sobre outros aspectos, mais especificamente sobre as aprendizagens, pode ser vista em artigos que mostram resultados em relação à construção de conceitos e a operações com números complexos (PUHL; LIMA, 2016a; PUHL; LIMA, 2016b) e, na dissertação (PUHL, 2016), tem-se o relato detalhado da pesquisa. Assim, este artigo complementa outros, pois se apresentaram indícios para dar visibilidade ao potencial de aprendizagem propiciado pelo OA, comprovando que este recurso auxiliou os estudantes a desenvolverem uma aprendizagem com sentido e compreensão.

Portanto, ao compartilhar a pesquisa ou partes dela, como se fez neste trabalho, tem-se a expectativa de que o OA possa ser utilizado e testado por outros provavelmente surgirão outros resultados, pois serão outros estudantes, com 
outros conhecimentos prévios, outros interesses pessoais e outra cultura. Segundo Alvez-Mazzotti e Gewandsznajder (1999, p. 181), "muitas vezes, resultados conflitantes entre pesquisas que focalizam um mesmo tópico são devidos à utilização de diferentes procedimentos, unidades de análise ou populações". A expectativa, com novas aplicações é de que tenha outros feedbacks, imprescindíveis para que seja possível aperfeiçoar o OA.

Pode-se afirmar, por fim, que as tecnologias são aliadas do professor, ao propiciar estratégias diferenciadas, adequadas para serem aplicadas em atividades presenciais ou em estudos à distância, com ou sem a presença de um professor $\mathrm{e}$ sempre com o foco na construção do conhecimento. Num futuro não distante, os recursos digitais podem deixar de ser uma ferramenta de apoio, passando a desempenhar um papel fundamental na construção do conhecimento, até mesmo sem a intervenção de um professor (MORAN; MASETTO; BEHRENS, 2002). Essa possibilidade foi, inclusive, reconhecida por um estudante, quando declarou que o que chamou a sua atenção no OA foi "o fato de podermos lidar com aplicativos como o GeoGebra de forma explicada, ou seja, sendo ajudado, orientado e conduzido pelo professor virtual", sendo este, então, um tema para ser abordado em uma pesquisa de doutorado. 


\title{
Complex numbers: an object of learning to teach and learn
}

\begin{abstract}
This article presents a cutout of a Masters research through which was created and analyzed a learning object (LO) as a digital resource for teaching complex numbers, in high school. The LO has the objective of promoting an active and meaningful learning, through interactions with application softwares available virtually, developed on Geogebra. On this article, we describe the LO and presents the result of evaluating this digital resource. The evaluation followed a model proposed by Tarouco, in which pedagogical and technical aspects are considered, using a scale for the evaluation of each criteria. Finally, the LO has shown good results, therefore there is the expectation that the LO will be used also by other teachers.
\end{abstract}

KEYWORDS: Complex numbers. Learning object. High school. Didactic resource. 
1 O OA desenvolvido por Monzon (2012) está disponível em: <http://www.ufrgs.br/espmat/disciplinas/numeros_complexos/>. Acesso em junho de 2018.

2 O OA desenvolvido por Pinto (2015) está disponível em: <https://www.geogebra.org/u/eustaquio+pinto>. Acesso em junho de 2018.

3 O OA desenvolvido por Puhl (2016) está disponível em: <http://matematicacomplexa.hol.es>. Acesso em junho de 2018.

4 Disponível em: <www.merlot.org>. Acesso em junho de 2018.

50 método de avaliação por escala consiste em atribuir uma nota de um a cinco aos critérios estabelecidos. Na escala proposta, a nota um representa discordar totalmente, dois, discordar, três significa não concordar nem discordar, quatro significa concordar, cinco, concordar totalmente e a opção sem resposta indica que o item não foi avaliado.

\section{REFERÊNCIAS}

ALMOULOUD, S. Ag. Didática e concepção de dispositivos informáticos educacionais. Revista de Informática Aplicada/Journal of Applied Computing, v. 3, n. 1, 2007. Disponível em: <http://ria.net.br/index.php/ria/article/view/15>. Acesso em: 2 jun. 2017.

AUDINO, D. F. Objetos de aprendizagem hipermídia aplicado à Cartografia escolar no sexto ano do ensino Fundamental em geografia. Dissertação (Mestrado em educação) - Universidade Federal de Santa Catarina, Florianópolis, 2012.

BARIN, C. S.; BASTOS, G. D.; MARSHALL, D. A elaboração de material didático em ambientes virtuais de ensino-aprendizagem: o desafio da transposição didática. Renote, Porto Alegre, v. 11, n. 1, 2013. Disponível em:

<http://seer.ufrgs.br/renote/article/view/41628>. Acesso em: 2 jun. 2017.

BATISTA, S. C. F. SoftMat: um repositório de softwares para matemática do Ensino Médio: um instrumento em prol de posturas mais conscientes na seleção de softwares educacionais. Dissertação (Mestrado em Ciências de Engenharia) Universidade Estadual do Norte Fluminense (UENF), Campos dos Goytacazes, Rio de Janeiro, 2004.

BELLEMAIN, F. A transposição informática na engenharia de softwares educativos. In: Seminário Internacional de Pesquisa em Educação Matemática (SIPEM), Serra Negra, São Paulo, p. 198-204, v. 1, 2000. 
BRASIL. Ministério da Educação. Secretaria de Educação Média e Tecnológica.

PCN + Ensino Médio: orientações educacionais complementares aos Parâmetros Curriculares Nacionais: ciências da natureza, matemática e suas tecnologias. Brasília: Ministério da Educação, 2002.

FERNANDEZ, R.; RIGO, S. J. Avaliação da promoção da aprendizagem em educação a distância, através do uso de um objeto de aprendizagem. Renote, Porto Alegre, v. 10, n. 3, 2012. Disponível em:

<http://seer.ufrgs.br/renote/article/view/36464>. Acesso em: 2 jun. 2017.

GRAVINA, M. A. Geometria dinâmica: uma nova abordagem para o aprendizado da Geometria. In: Simpósio Brasileiro de Informática na Educação, Belo Horizonte, 1996. Disponível em:

<http://www.ufrgs.br/espmat/disciplinas/geotri/pdf/maria-alice_geometriadinamica1996-vii_sbie.pdf>. Acesso em: 2 jun. 2017.

MASSETO, M. T. Mediação Pedagógica e Tecnologias de Informação e Comunicação. In: MORAN, J. M.; MASETTO, M. T.; BEHRENS, M. A. (Org.). Novas tecnologias e mediação pedagógica. Campinas (SP): Papirus, p.11-72, 2013.

MELLO, S. Q.; SANTOS, R. P. O ensino de matemática e a educação profissional: a aplicabilidade dos números complexos na análise de circuitos elétricos. Acta Scientiae, Canoas, v. 7, n. 2, 2005. Disponível em:

<http://www.periodicos.ulbra.br/index.php/acta/article/view/179>. Acesso em: 2 jun. 2017.

MONZON, L. W. Números Complexos e funções de variável complexa no ensino médio uma proposta didática com uso de objeto de aprendizagem. Dissertação (Mestrado Profissional) - Universidade Federal do Rio Grande do Sul, Porto Alegre, 2012. Disponível em: <http://www.lume.ufrgs.br/handle/10183/56236>. Acesso em: 2 jun. 2017.

MORAN, J. M.; MASETTO, M. T.; BEHRENS, M. A. Novas tecnologias e mediação pedagógica. Campinas, SP: Papirus, 2002.

MORETTO, V. P. Prova: um momento privilegiado de estudo, não um acerto de contas. Rio de Janeiro: Lamparina, 2007.

PUHL, C. S.; LIMA, I. G. de. Uma atividade potencialmente significativa: diferenciando números reais dos números complexos. Revista Caderno Pedagógico, Lajeado, v. 13, n. 1, 2016a. Disponível em: <http://www.univates.br/revistas/index.php/cadped/article/view/987>. Acesso em: 2 jun. 2017. 
PUHL, C. S.; LIMA, I. G. de. Uma sequência didática para compreender a potenciação e a radiciação de números complexos. REMAT: Revista Eletrônica da Matemática, Caxias do Sul, v. 2, n. 1, 2016b. Disponível em:

<https://periodicos.ifrs.edu.br/index.php/REMAT/article/view/1283>. Acesso em: 2 jun. 2017.

PUHL, C. S. Números complexos: interação e aprendizagem. Dissertação (Mestrado) - Universidade de Caxias do Sul, Caxias do Sul, 2016. Disponível em: <https://repositorio.ucs.br/xmlui/handle/11338/1144>. Acesso em: 2 jun. 2017.

TAROUCO, L. M. R. Avaliação de objetos de aprendizagem. 2004. Disponível em: <http://penta2.ufrgs.br/edu/objetosaprendizagem/>. Acesso: 2 jun. 2017.

WILEY, D. The instructional use of learning objects. 2000. Disponível em <http://reusability.org/read/>. Acesso: 2 jun. 2017.

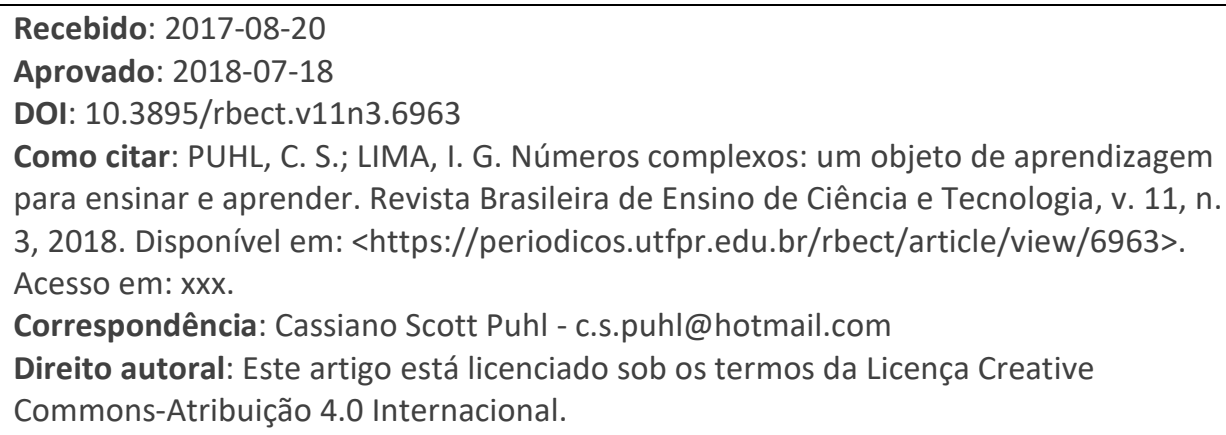

